Int. J. Dev. Biol. 50: 255-266 (2006)

doi: $10.1387 /$ ijdb.052044di

\title{
Mechanical control of tissue morphogenesis during embryological development
}

\author{
DONALD E. INGBER* \\ Vascular Biology Program, Departments of Pathology and Surgery, Children's Hospital and Harvard Medical School, Boston, MA, USA
}

\begin{abstract}
Twenty years ago, we proposed a model of developmental control based on tensegrity architecture, in which tissue pattern formation in the embryo is controlled through mechanical interactions between cells and extracellular matrix (ECM) which place the tissue in a state of isometric tension (prestress). The model proposed that local changes in the mechanical compliance of the ECM, for example, due to regional variations in basement membrane degradation beneath growing epithelium, may result in local stretching of the ECM and associated adherent cells, much like a "run-in-a-stocking". Cell growth and function would be controlled locally though physical distortion of the associated cells, or changes in cytoskeletal tension. Importantly, experimental studies have demonstrated that cultured cells can be switched between different fates, including growth, differentiation, apoptosis, directional motility and different stem cell lineages, by modulating cell shape. Experiments in whole embryonic organ rudiments also have confirmed the tight correlation between basement membrane thinning, cell tension generation and new bud and branch formation during tissue morphogenesis and that this process can be inhibited or accelerated by dissipating or enhancing cytoskeletal tension, respectively. Taken together, this work confirms that mechanical forces generated in the cytoskeleton of individual cells and exerted on ECM scaffolds, play a critical role in the sculpting of the embryo.
\end{abstract}

KEY WORDS: cytoskeleton, tensegrity, prestress, integrin, mechanotransduction, tension

\section{Introduction}

Embryogenesis - how the tissues and organs of the developing embryo take their miraculous forms - is currently explained in terms of genes, hormones and chemical gradients. However, when the field of embryology first emerged in the latter part of the nineteenth century, developmental mechanisms were explained largely in mechanical and physical terms (Lenoir, 1982, Thompson, 1952). These structural explanations fell by the wayside when biochemistry and molecular biology took hold and began to blossom. The power to switch on and off different embryological programs through genetic engineering clearly has confirmed the importance of specific genes for developmental control. But identification of a light switch on a factory floor does not explain how a finely crafted automobile is constructed. Similarly, although we have solved the Human Genome, we still do not understand how embryonic tissues and organs are physically constructed with three-dimensional (3D) forms optimally designed to carry out their specialized functions.

Twenty years ago, we proposed that tissue morphogenesis and embryological development might be controlled mechani- cally (Ingber and Jamieson, 1985, Huang and Ingber, 1999). However, rather than macroscale forces (e.g., osmotic forces, surface tension) being the critical players as assumed at the turn of the last century, we suggested that these developmental processes were guided by micromechanical forces that are generated within and exerted by, the acto-myosin cytoskeleton of the individual cells that comprise the forming tissues. Local changes in the mechanical force balance within cells and tissues may, in turn, alter cellular responses to particular soluble hormones and growth stimuli and thereby establish the regional variations in cell form and function that drive tissue patterning.

In this article, embryological development is first described from a "physical perspective" for those readers who are unfamiliar with structural thinking. This is followed by a more detailed description of the micromechanical model of developmental control and a review of recent in vitro and in vivo studies that provide experimental support for this model. New insights into the molecu-

Abbreviations used in this paper: ECM, extracellular matrix; 3D, threedimensional; ROCK, Rho-associated kinase; CNF-1, cytotoxic necrotizing factor 1 . 
lar basis of cellular mechanotransduction - how cells sense mechanical forces and convert them into changes in intracellular biochemistry - also will be discussed, as well as how physical forces control cellular decision-making at the level of the genomewide gene regulatory network. Finally, the larger implications of these findings for developmental biology and embryology are considered.

\section{Mechanical forces as developmental regulators in the embryo}

The shaping of the living embryo begins with a process of cell multiplication through division after fertilization of the ovum. Initially, a round cellular aggregate (morula) forms and undergoes a process known as "compaction" because all of the daughter cells actively generate tensional forces within contractile (actomyosin) microfilaments in their intracellular cytoskeleton and apply these forces to their adhesion sites (junctional complexes mediated by cadherin receptors) on the surfaces of neighboring cells (De Vries et al., 2004). Cells polarize when they adhere and pull against a rigid substrate (Ingber et al., 1986) or another cell (Rodriguez-Boulan et al., 1983). Thus, the first polarized (anisotropic) cell structures form at the 8-cell stage of embryological development because cells on the inside of the multi-cellular cluster are pulled on by cells from all directions, whereas those on the surface of the aggregate have no contacts with other cells on their external surface. This mechanical contraction process (i.e., compaction of the morula) is an absolute requirement for subsequent preimplantation development (Riethmacher et al., 1995). Cell contraction in the morula is regulated by the small GTPase Rho (Clayton et al., 1999), which similarly controls cell contractility, as well as actin polymerization, in adult cells (Kawano et al., 1999, Kimura et al., 1996, Li and Higgs, 2003).

These inner and outer cells then rearrange to form a hollow ball (blastula). In certain embryos (e.g., chick) that develop adherent to a large yolk sac that is stiffer than the growing ball of cells, the cells integrate this relatively rigid substrate into their overall structure as an internal surface and rearrange to form a hollow disk rather than a sphere. This hollow cluster of cells then invaginates in on itself, as one might push in on a balloon with a finger, to form a two layered structure in a process known as gastrulation: the outer layer represents the ectoderm and the inner, the endoderm. Organization of the ectoderm and endoderm is quickly followed by the formation of the third primary cell layer - the mesoderm - through the processes of differentiation (specialization) and directional migration, with cell division being used to simultaneously expand all three populations.

\section{Extracellular matrix as a developmental regulator}

Although it is essentially ignored in most descriptions of tissue development, one of the most important cellular behaviors that permits the formation of the first specialized tissue forms (i.e., planar ectoderm and endoderm) is the production of extracellular matrix (ECM) attachment scaffolds that hold together cells within all solid tissues. In the case of the epithelial tissues, this ECM is called the "basement membrane" because cells sit on top of it in close apposition, much like eggs in an egg carton. In the central mesodermal space that connects adjacent epithelial tissues (i.e., the "connective tissue" space), the ECM takes on the form of a porous 3D lattice and is known as "interstitial matrix".

These molecular ECM scaffolds function much like external construction scaffolds composed of metal struts and wood planks that are used by building contractors. Construction workers use them as work platforms because they can be repeatedly extended as the building grows in height and width to cover new work areas and extension of these platforms is often rate-limiting for building expansion. The same is true for living tissues.

Every time a new epithelium is formed (starting from the emergence of the ectoderm and endoderm), it is simultaneously accompanied by accumulation of a new basement membrane. For example, the basement membrane protein, laminin, is first observed in a punctate pattern in the intercellular spaces between cells in the 8 cell stage embryo whereas other basement membrane proteins, including fibronectin, heparan sulfate-proteoglycan and type IV collagen appear later in development (Leivo, 1983). It is only when type IV collagen molecules self assemble into a chicken wire-like mesh (Yurchenco and Ruben, 1988) in the late blastocyt that the other ECM molecules become organized into the first planar basement membranes (Leivo, 1983). Anchorage of the growing embryonic cells to common ECM scaffolds causes the individual cells to reorient in a consistent manner, thereby resulting in the formation of the first polarized epithelial monolayers: the ectoderm and endoderm. New basement membrane production is also required during later stages of development for formation of secondary epithelium from primary mesenchyme (e.g., during kidney tubulogenesis; Ekblom et al., 1980) and subsequent changes of tissue form require progressive basement membrane remodeling (Bernfield and Banerjee, 1978), as will be described in more detail below. Thus, as in any building project, a rudimentary construction scaffold must be assembled before specialized 3D tissue structures can be raised or remodeled in the embryo.

In contrast to work platforms used in buildings, ECM scaffolds are flexible (i.e., rather than rigid) and they undergo continual turnover (addition and removal) of their individual biochemical constituents. Cells produce these 3D cellular adhesive scaffolds in the embryo by secreting ECM molecules that self-assemble into higher order structures, including nanometer-sized cables (collagen fibrils), struts (larger cross-linked collagen bundles), nets (porous sheets of basement membrane collagens) and acqueous gels (hydrogels composed of glycosaminoglycans and filamentous collagens). Besides complexing with each other, all of these molecules also bind cell surface ECM receptors, known as "integrins" (Ruoslahti, 1991) and thereby physically anchor both epithelial and underlying mesenchymal cells to a common ECM scaffold (i.e., basement membrane). Also, the ECMs are generally not removed after tissue formation because they provide a critical structural function: although they are flexible, they are stiffer than the cells and hence they can resist cell-generated forces and hold tissues stable in non-spherical (e.g., planar) forms (Moore etal., 1995). Thus, one of the fundamental rules that has often been overlooked in past models of embryological development is that an ECM construction scaffold is commonly assembled and set in place before any spatially-ordered 3D tissue structure is raised or remodeled and that cells physically interact with this scaffold by exerting traction forces on their ECM adhesions. 
As development proceeds throughout gastrulation and during later stages of embryogenesis, these three layers are sculpted into the general layout of the embryo (e.g., head, eyes, spine, internal organs, tail) through a mechanically active process involving pulling, pushing, bending and twisting. Changes in the balance of mechanical forces within the cytoskeletons of the embryo's constituent cells drive all of these structural changes and impact the orientation of cell movements and formation of specialized tissues, as well as the overall polarity of the whole embryo (Beloussov et al., 1975, 1990, 2000, Keller, 1980, Gordon and Brodland, 1987, Adams etal., 1990, Farge, 2003, Keller etal., 2003). Cells may pull themselves forward by exerting cytoskeleton-based tractional forces on their ECM adhesions, or push themselves outward in a particular direction by osmotically swelling as a group within a surrounding non-extensible ECM sheath (e.g., during notochord formation) (Adams et al., 1990). New stable tissue forms emerge when these forces come into balance because they are resisted by larger scale ECM structures (e.g., basement membranes, cross-linked collagen bundles) and by the contractile or swelling forces of opposing cells (Ingber and Jamieson, 1985, Hardin and Keller, 1988). However, in all cases, stability results from the establishment of a state of isometric tension, such that the ECM experiences a tensile prestress. In fact, this is true throughout adult life; this is why surgeons need to suture an incision to hold the cut edges of the tissue together. Thus, tissue pattern formation is governed by both cell-generated forces and the mechanical properties of the local tissue microenvironment.

Once the general layout of the embryo has been established, the distinct tissues and organs that provide all of the specialized functions of the body must form. Construction of these more complex parenchymal structures (e.g., branching capillary networks, lobular epithelial glands, etc.) results from progressive growth and remodeling of more simple-shaped, primitive epithelial tissues (e.g., sheets, tubes) and their tightly associated ECMs that formed during the earlier developmental stages. This process is controlled through active interactions between closely apposed epithelial and mesenchymal tissues.

Over twenty five years ago, researchers noted that localized regions of growing epithelial and endothelial tissues that exhibit the highest rate of basement membrane remodeling and growth, also display the highest cell proliferation rates; these locations correlated precisely to the tips of growing epithelial buds and capillary branch points (Ausprunk and Folkman, 1977, Bernfield and Banerjee, 1978). In contrast, nearby regions of the same tissue that formed the future "clefts" between the expanding buds were the sites where more rigid fibrillar ECM molecules were deposited; these ECM fibrils inhibited epithelial basement membrane turnover (David and Bernfield, 1979). Because cell growth also was low in these cleft regions, these areas remained relatively constant in size while the neighboring epithelial buds that exhibited high rates of both basement membrane deposition (extension) and cell proliferation expanded outward, as can be seen for example during lung development (Fig. 1A). This process is repeated along the sides of the newly formed buds and sprouts and then the whole process is repeated over time, resulting in the development of fractal-like patterns characteristic of whole living tissues (Fig. 1B).

Similar local tight coupling between basement membrane turnover and cell motility, as well as growth, mediate capillary sprout outgrowth during branching morphogenesis in the vascular system, or what is known as "angiogenesis" (Ausprunk and Folkman, 1977, Ingber, 2002). Branching morphogenesis in mammary gland also can be either enhanced or inhibited by accelerating or slowing ECM turnover, respectively, using modulators of matrix metalloproteinases that degrade ECM (Simian et al., 2001). Thus, the presence of an intact basement membrane appears to stabilize epithelial tissue form, whereas changes in tissue pattern are driven by regional differentials in basement membrane turnover that, in turn, are tightly coupled to local changes of cell growth and migration.

\section{Micromechanical model: tension as an informative force}

Initially, it was thought by many that localized tissue outgrowth (e.g., epithelial budding) results from increased proliferation, which would cause cells to pile up and physically push (compress) the basement membrane outward, thereby forming a bud. In contrast, we proposed an alternative explanation: this regional form of morphogenetic control may be regulated by changes in local tensional forces (Fig. 2)(Ingber and Jamieson, 1985, Huang and Ingber, 1999). This model was based on the observation that all cells in the body actively generate tension in their acto-myosin cytoskeleton (Harris etal., 1980), just like in muscle and they exert these forces on their adhesions to neighboring cells and to
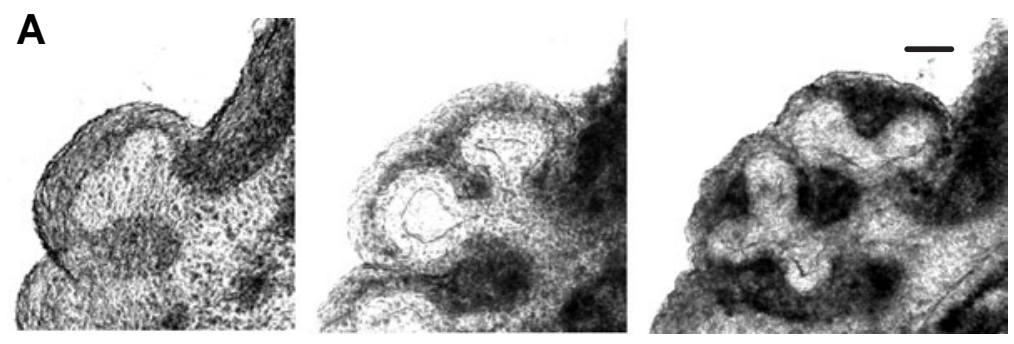

\section{B}

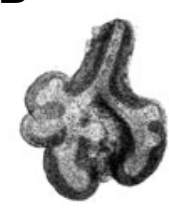

0

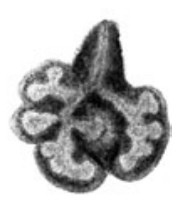

12

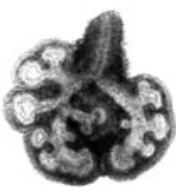

24

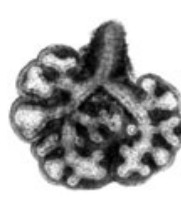

36

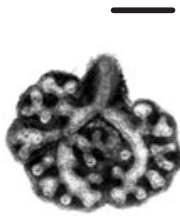

48
Time (hr)

Fig. 1. Normal branching morphogenesis in embryonic mouse lung. Lung rudiments were surgically removed on day E12, cultured for 48 hours and monitored by serial light microscopy. (A) High magnification views of individual epithelial buds at 0, 24 and 48 h of culture (left to right) showing that normal epithelial branching morphogenesis results from progressive bud enlargement and expansion, followed by cleft formation at the tip of each bud; this results in formation of two or three smaller buds (scale bar, $100 \mu \mathrm{m}$ ). (B) Photographs recorded every 12 hours during cultures of the organ rudiments showing fractallike patterns formed by the branching epithelium of growing mouse lung (scale bar, $500 \mu \mathrm{m}$ )(Moore et al., 2005). 


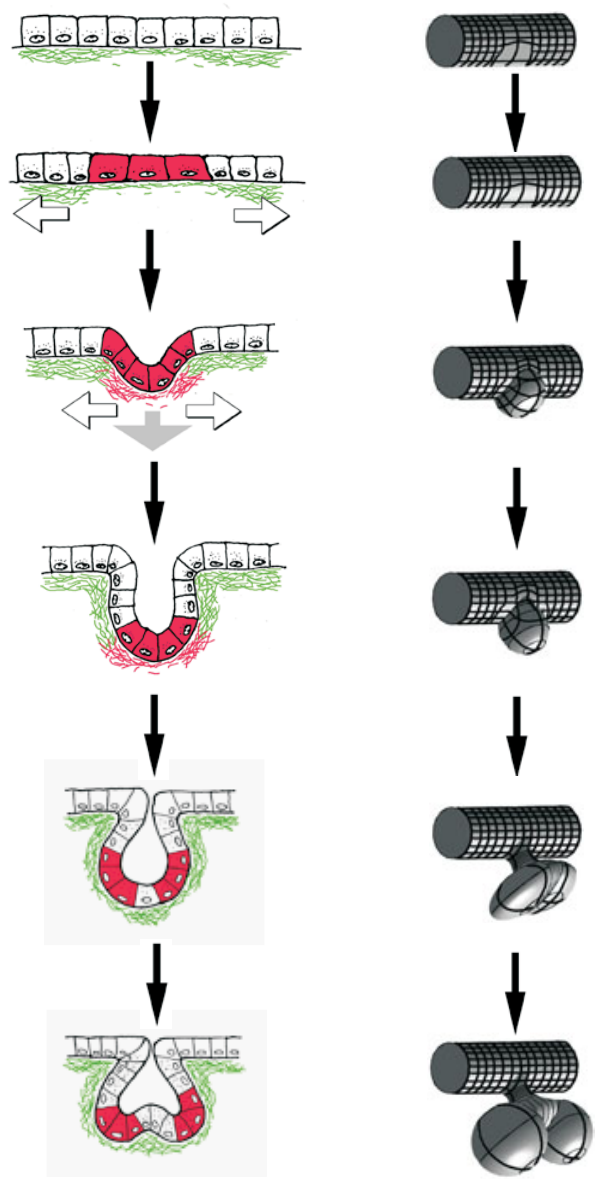

Fig. 2. Micromechanical model of morphogenetic control during epithelial development. (Left) Local increases in ECM turnover beneath the epithelial cell monolayer result in formation of focal defects in the basement membrane (green) which stretch and thin locally due to the contraction and pulling of neighboring adherent epithelium (white arrows) and underlying mesenchyme (gray arrow) which prestress the ECM. Red cells indicate those cells adherent to the region of the basement membrane which stretches like a "run-in-a-stocking"; these cells will distort or experience increases in cytoskeletal tension relative to surrounding cells and thus, become preferentially sensitive to growth stimuli. Cell mass expansion and ECM extension are tightly coupled because cell division is paralleled by new basement membrane deposition (red); this leads to new bud formation in this localized region. (Right) Theoretical mechanical strain distributions within the basement membrane of the developing epithelium at corresponding times during branching morphogenesis. Increased spacing between the strain field lines indicates regions where the basement membrane thins and experiences increased mechanical strain (distortion). These regions of increased strain correlate precisely to regions of epithelial expansion and new bud formation.

surrounding ECM scaffolds. Because the ECM is under tension or "prestressed", degradation or partial unraveling of it within a small region will result in local stretching of the ECM, much like a run in a woman's stocking stretches out more than the rest (Fig. 2). Cells anchored to the distended region of the basement membrane will also stretch, whereas neighboring cells on intact ECM will remain unchanged. If cell stretching promotes growth, as suggested by earlier in vitro studies (Folkman and Moscona, 1978), then this could generate the local cell growth differentials that drive regional tissue expansion and thereby produce complex 3D pattern formation.

Reiteration of this process in time and space would lead to the fractal-like patterns found in all tissues and species (Fig. 3). Similar local variations in mechanical force balances between cells that form cell-cell junctions within the same tissue could produce regional variations in cell growth and function in a similar manner, as is observed during earlier stages of embryo formation (Farge, 2003). Conversely, if the ECM is completely degraded, cell tractional forces will no longer be resisted and the cells will retract, round and die due to loss of anchorage (Chen etal., 1997). In this manner, tissues would be sculpted as a result of the action of physical forces, generated by the tissues' constituent cells, which spatially constrain growth. In fact, more recent studies of organ development have revealed that epithelial bud outgrowth begins before cell proliferation rates increase (Nogawa et al., 1998). Thus, this theoretical micromechanical model has become even more relevant. In the sections that follow, I will review experimental data that provide further support for this model.

\section{Shape-dependent control of cell fate switching}

A key element of the micromechanical model is that stressdependent changes in cell shape or cytoskeletal tension act locally to regulate cell phenotype. In fact, studies carried out with various types of cultured cells have confirmed that changes in the balance of mechanical forces between cells and the ECM control all of the key cell behaviors that are responsible for tissue development. For example, cells make entirely different fate decisions, such as whether to grow, differentiate or die (i.e., undergo programmed cell death or "apoptosis"), depending on the adhesivity or mechanical compliance of their ECM substrate and thus, the degree to which they physically extend (Folkman and Moscona, 1978, Ben-Ze'ev etal., 1980, Glowacki etal., 1983, Li et al., 1987, Ben-Ze'ev et al., 1988, Ingber and Folkman, 1989, Opas, 1989, Ingber, 1990, Mooney et al., 1992, Singhvi et al., 1994, Chen etal., 1997, Dike et al., 1999, Niland etal., 2001). This can be accomplished by varying the density of immobilized ECM molecules on otherwise non-adhesive dishes; changing the flexibility of ECM gels; or creating planar ECM islands with defined size and shape on the micrometer scale using microfabrication techniques (Fig. 4).

In general, when the shape of epithelial cells, endothelial cells or fibroblasts is modulated by any of these methods, spread cells proliferate; fully retracted cells undergo apoptosis and die; and moderately spread cells remain quiescent and differentiate (Fig. $4 \mathrm{~A}-\mathrm{I})$. The overall shape of smooth muscle and endothelial cells also feeds back to control the level of traction forces they exert when stimulated with contractile agonists and this influences the size and number of focal adhesions they form on ECM (Tan et al., 2003, Chen et al., 2004, Polte et al., 2004). Focal adhesions are the specialized anchoring sites where intracellular contractile microfilaments insert on clustered transmembrane integrin receptors through binding of various actin-associated proteins (e.g., talin, vinculin, $\alpha$-actinin, zyxin) and thereby mechanically couple the cytoskeleton to the ECM; many signal transduction molecules also concentrate in these same regions (Geiger et al., 2001). 
Interestingly, the mechanical compliance of the ECM and the direction of the physical distortion also influence the position in which cells will assemble their focal adhesions and the orientation in which they will move (Beningo et al., 2001, Parker et al., 2002, Wang et al., 2002, Brock et al., 2003). For example, cells cultured on ECM islands with square or triangular shapes preferentially extend new motile processes (e.g., lamellipodia) from their corners and these processes are more likely to form at corners with angles that are more acute than obtuse in shape; in contast, cells on circular islands do not display any obvious directional preference (Fig. $4 \mathrm{~J}$-L). This ability to orient cell movement through cell distortion likely plays a central role in control of tissue patterning, as evidenced by the finding that tension application similarly promotes capillary outgrowth and elongation along the tension field lines in 3D matrices (Korff and Augustin, 1999). Cell-generated tensional forces also direct nerve outgrowth, axon fate and $3 \mathrm{D}$ organization of neuron arbors in vivo as well as in vitro (Bray, 1979, Joshi et al., 1985, Condron and Zinn, 1997, Lamoureux et al., 2002). In contrast, complete basement membrane dissolution that leads to cell retraction and rounding produces tissue involution during angiogenesis inhibition (Ingber etal., 1986), as well as during regression of Mullerian duct (Trelstad et al., 1982) and mammary gland (Wicha et al., 1980). Recent studies also have revealed that mesenchymal stem cells can be reliably switched between different lineages (e.g., bone versus fat) through ECMdependent changes of cell shape (McBeath et al., 2004) and that cells are tuned mechanically so that they preferentially differentiate on ECM with a mechanical stiffness similar to that of their natural tissue (Engler et al., 2004).

Nevertheless, these different shaped cells can exhibit similar transmembrane signaling behavior in response to binding to soluble mitogens (Ingber etal., 1990) or insoluble ECM molecules (Yan et al., 2000) and to application of local mechanical forces (Meyer et al., 2000). Thus, one of the central tenets of the micromechanical model of developmental control - that cell shape

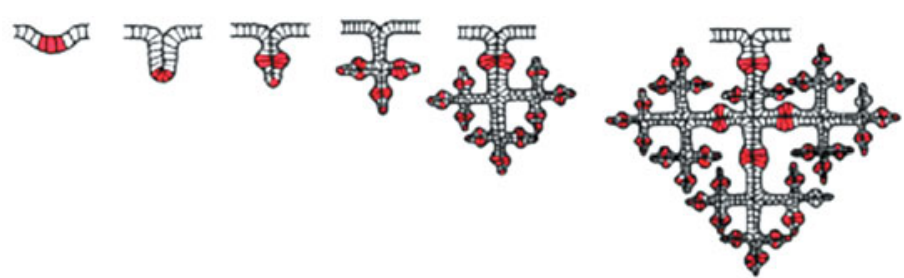

Fig. 3. Fractal tissue patterns emerge through reiterative branching. More complex tissue structures result from repeated use of the growth rules described in Fig. 2. Red cells are localized in regions where cell proliferation rates are increased relative to surrounding areas due to local changes in mechanical stress distributions, even though soluble growth factors may be present throughout the entire tissue.

distortion acts locally to control cell growth and function - appears to be true, at least based on results from in vitro experiments.

\section{Mechanical control of tissue morphogenesis in embry- onic lung}

Importantly, we recently confirmed that tissue morphogenesis can be controlled in embryonic tissues by altering the cellular mechanical force balance (Moore et al., 2005). Cytoskeletal force generation was modulated in whole lung organ rudiments cultured for 48 hours after isolation from embryonic mice on day E12 using inhibitors of Rho-associated kinase (ROCK), myosin light chain kinase, myosin ATPase and microfilament integrity, or a Rho stimulator (CNF-1). When cytoskeletal tension generation was suppressed with the ROCK inhibitor Y27632 or any of the other inhibitory agents, epithelial budding was inhibited (Fig. 5) and the local thinning of the basement membrane that is normally observed in regions of new epithelial bud formation was lost (Fig. 6 ). By contrast, when cytoskeletal tension was increased by activating Rho using CNF-1, lung branching was accelerated (Fig. 5).
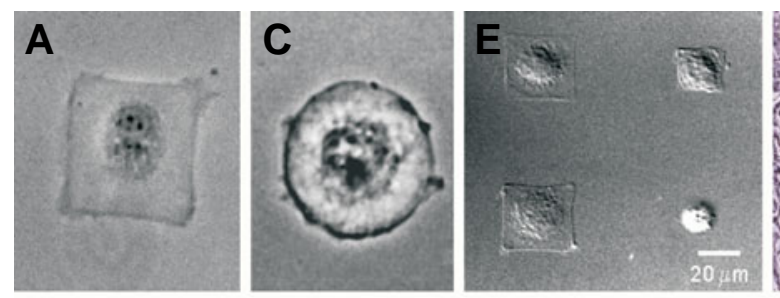

B

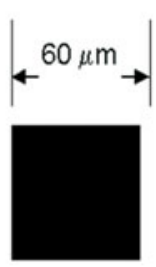

D

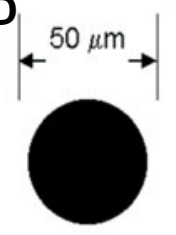

$\mathbf{F}$

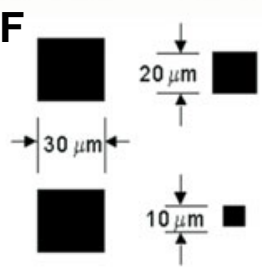

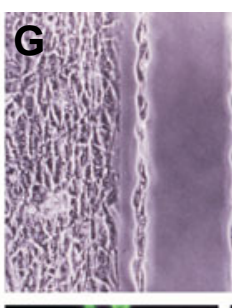
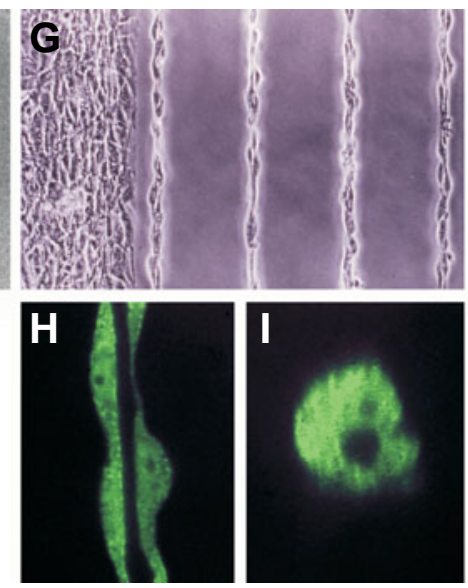
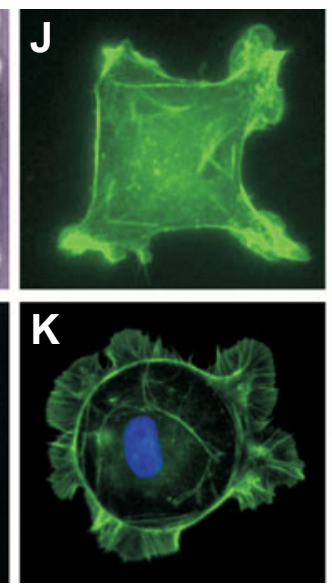

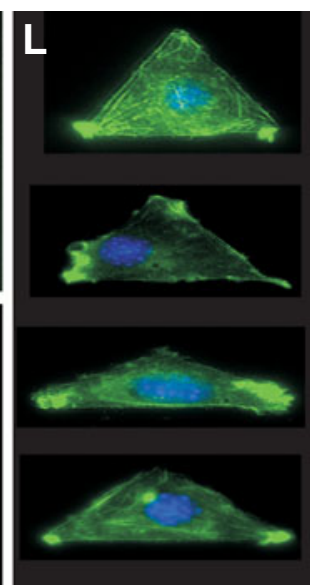

Fig. 4. Cell shape-dependent switching between cell fates on microfabricated ECM islands. (A-F) Endothelial cells spread to take on the shape of micrometer-sized ECM islands coated with fibronectin that were created using a microcontact printing technique; the design of the substrates is shown in the lower panels (B,D,F). Cells that adhere and spread on large islands proliferate whereas those that are cultured on the smallest islands (<20 4 m diameter) undergo apoptosis (Chen et al., 1997). (G-I) When the same endothelial cells are cultured on microfabricated ECM islands in the form of long thin lines (30 $\mu \mathrm{m}$ wide) that promote only a moderate degree of spreading and support cell-cell contact formation, the cells switch on a differentiation program and form hollow capillary tubes (Dike et al., 1999). (J-L) When cells cultured on ECM islands of different geometries are stimulated with motility factors, they preferentially extend new lamellipodia from their corners. New motile processes are more often observed in corners with acute angles rather than obtuse angles; cells on circular islands do not display any directional bias (Parker et al., 2002, Brock et al., 2003). 


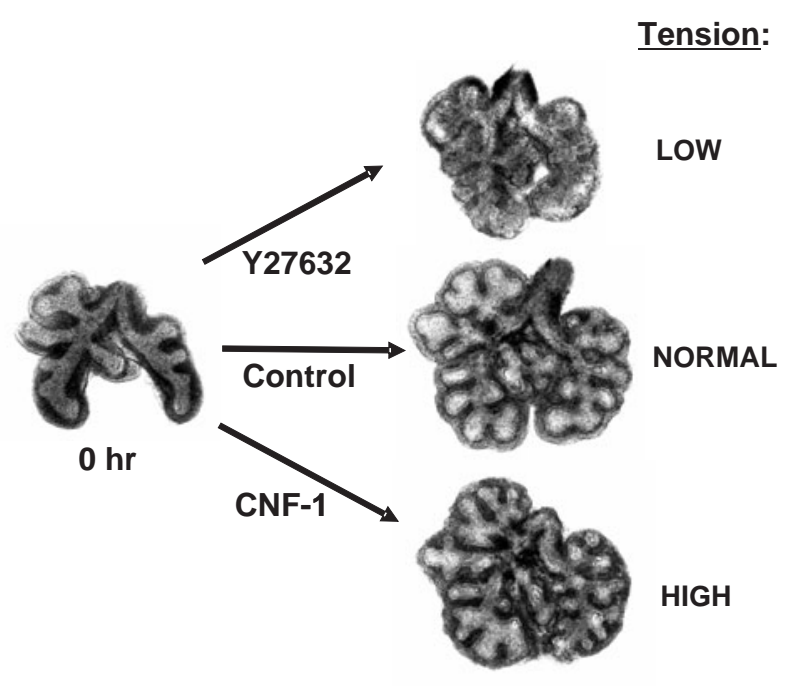

$48 \mathrm{hr}$

Fig. 5. Control of lung morphogenesis by altering cytoskeletal tension through modulation of Rho signaling. Epithelial branching was inhibited in embryonic mouse lung rudiments when cytoskeletal tension was dissipated by treatment with the ROCK inhibitor, Y27632 (top). In contrast, lung branching was significantly increased when cytoskeletal tension was raised by treatment of lungs with the Rho activator, CNF-1 (bottom) (Moore et al., 2005).

These effects on morphogenesis were shown to correlate more closely with effects on cell contractility, than on the level of Rho activation, as determined using biochemical assays (i.e., for myosin light chain phosphorylation and Rho activity)(Moore et al., 2005). Immunohistocytochemical studies using fluorescent-phalloidin also revealed that mesenchymal cells directly beneath the thinnest regions of the epithelial basement membrane where new buds will form normally exhibit a higher level of actin alignment (i.e., consistent with a higher level of contractility) than neighboring cells. Moreover, tension dissipation using the ROCK inhibitor resulted in a complete loss of filamentous actin staining, whereas stimulation of contractility greatly enhanced actin bundle formation in these regions. We also found that increasing and decreasing cell tension respectively inhibited and promoted angiogenesis (capillary elongation) within the neighboring connective tissue. Yet, the total level of cell proliferation within the mesenchyme and epithe-
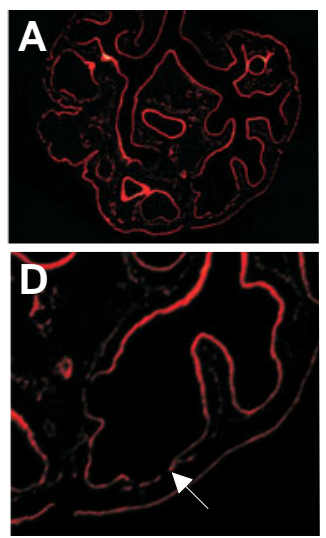

Control
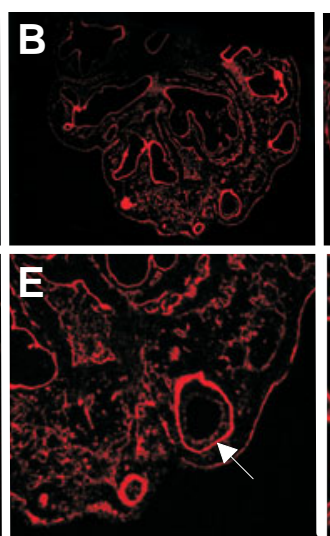

Y27632
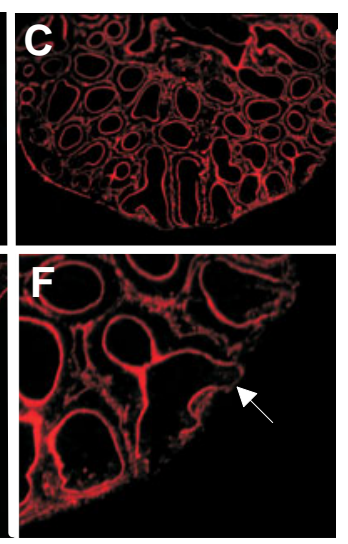

CNF-1 lium did not change significantly in these studies; only the spatial pattern of growth was altered (Moore et al., 2005).

These data suggest that changes in cytoskeletal tension mediated by Rho signaling through ROCK play an important role in the establishment of the regional variations in cell growth and ECM remodeling that drive epitheliogenesis and angiogenesis during embryonic lung development. The finding that the epithelial basement membrane did not thin when tension was inhibited is consistent with the "run-in-the-stocking" analogy: a stocking will not spread out and thin locally to form a run unless it is tensed. These data therefore provide strong experimental support for the micromechanical model of tissue development described above. Moreover, tensional forces exerted on capillary blood vessels, in part as a result of expansion of neighboring epithelial buds, apparently served to promote the elongation of these microvessels specifically in regions of lobular expansion (Fig. 7). This mechanical coupling may ensure that the epithelial surface remains well vascularized throughout all subsequent phases of lung development. Long-distance transfer of mechanical forces between the different tissues that comprise growing organs may therefore spatially orchestrate the growth and expansion of these neighboring tissues and thereby help to build higher order organ structures (i.e., whole lung) with integrated form and function.

\section{Cellular mechanotransduction}

How might this work? How can altering the level of tensional forces in the cytoskeleton, or the degree to which a cell physically spreads on ECM alter its growth and function? Our group and others have shown that transmembrane receptors, such as integrins and cadherins, that physically couple cells to ECM and to other cells, respectively, provide preferred paths for mechanical signal transfer across the cell surface and to (and from) the cytoskeleton (Wang etal., 1993, Schmidt etal., 1993, Potard etal., 1997, Geiger et al., 1995,2001). This is important because the cytoskeleton is more than a structural scaffold that generates tension: it also orients much of the biochemical machinery of the cell, including many of the enzymes and substrates that mediate signal transduction, glycolysis, protein synthesis, RNA processing and DNA metabolism (Ingber, 1993b).

In particular, the specialized cytoskeletal complexes that form the backbone of focal adhesions and cell-cell adhesions are major cellular sites for solid-phase signaling (Plopper etal., 1995, Miyamoto

Fig. 6. Loss of regional variations of basement membrane thickness when tension is inhibited. Immunofluorescence staining for basement membrane component, laminin, within lung rudiments cultured for $48 \mathrm{~h}$ in the absence or presence of Y27632 or CNF-1, shown at low (A-C; scale bar, $250 \mu \mathrm{m}$ ) and high (D-F; scale bar, $100 \mu \mathrm{m})$ magnification. Arrow indicates a region of the basement membrane at the periphery of one bud within each gland in ( $D$ F). (A,D) In the control gland, the region of the basement membrane underlining the peripheral border of the epithelium where the most rapid cell proliferation is observed is thinner than that in the more proximal regions of the same gland. (B,E) Inhibition of cytoskeletal tension by treatment with Y27632 resulted in loss of the normal differentials in basement membrane structure. A thick continuous linear pattern of laminin staining is now observed surrounding all epithelium. (C,F) Basement membrane thinning was maintained at the periphery of growing epithelium in lungs treated with the Rho activator CNF-1. 
et al., 1995, Geiger et al., 1995,2001). For example, when mechanical forces are applied to integrin receptors or cadherins (e.g., using magnetic forces), cellular biochemistry and gene expression are altered in a stress-dependent manner (Meyer et al., 2000, Ko et al., 2001). Mechanical forces applied to these receptors by this mechanism, optical tweezers, shear stress or other manipulation methods activate many signaling pathways within these specialized cytoskeletal anchoring sites (i.e., focal adhesions and cell-cell junctions), including protein tyrosine phosphorylation, ion fluxes, cAMP and G protein signaling (Geiger et al., 2001, Alenghat and Ingber, 2002). By contrast, the same force produces no effect if it is applied to a peripheral membrane receptor (Meyer et al., 2000). Thus, cells use specific transmembrane receptors that mechanically couple the cytoskeleton to extracellular structures - ECM and other cells - to mediate mechanochemical transduction.

However, a local stress also may produce global structural responses inside the cell because, like the whole tissue, the cytoskeleton is itself a prestressed network structure on a smaller size scale. Self-supporting structures that gain their mechanical stability through the existence of an internal tensile prestress are known as "tensegrity" structures (Fuller, 1961); we therefore proposed that cells and tissues use tensegrity architecture to structure themselves (Ingber et al., 1981, Ingber and Jamieson, 1985, Ingber, 1993a, Ingber, 2003a). This insight formed the basis for the micromechanical model of tissue morphogenesis described above (Ingber and Jamieson, 1985). But another novel feature of these tensed network structures is that a local stress can produce structural rearrangements throughout the entire network and at different size scales (e.g., from tissue to molecular), if mechanical connectivity is maintained (Wang et al., 1993, Ingber, 2003a).

Cells exhibit this same behavior: force application to integrins on the surface membrane results in stress-dependent displacements of microfilaments, mitochondria, focal adhesions at the opposite pole of the cell and even molecular realignment of nucleoli inside the nucleus (Maniotis et al., 1997; Wang et al., 2001, Hu et al., 2003). Moreover, as predicted by the cellular tensegrity model, this response is mediated by cytoskeletal filaments and modulated by the level of prestress in the cytoskeleton ( $\mathrm{Hu}$ et al., 2003,2004a,2004b, Rosenblatt et al., 2004). Thus, a local force may alter cell behavior by influencing biochemical activities at multiple sites and cell spreading could influence cellular biochemistry in a similar manner.

In fact, although cells may sense mechanical forces transmitted from ECM locally within their focal adhesions, cells integrate these signals with other information relating to the overall structural state of the cell and cytoskeleton before orchestrating a concerted functional response. For example, when integrin receptors are mechanically stressed on spread versus round cells, similar signaling in focal adhesions (e.g., cAMP production) is observed (Meyer et al., 2000). Yet, the flattened cell integrates this signal with other cues conveyed by its overall physical state and switches on a proliferation program, whereas the round cells shut off growth and undergoes apoptosis (Chen et al., 1997). The degree to which an endothelial cell spreads also feeds back to regulate the Rho signaling cascade leading to changes in cell contractility (Polte et al., 2004), as well as progression through the late $\mathrm{G} 1 / \mathrm{S}$ restriction point of the cell cycle (and hence cell proliferation) (Huang et al., 1998, Mammoto et al., 2004). Furthermore, this effect is mediated by structural changes in the actin cytoskeleton (Mammoto et al.,

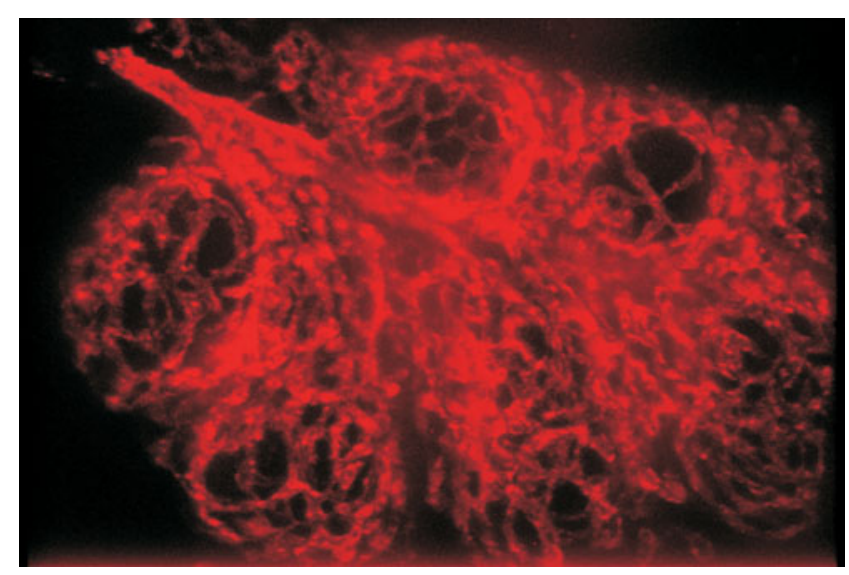

Fig. 7. Mechanical coupling between epitheliogenesis and angiogenesis. Immunofluorescence micrograph of a whole mount preparation of a cultured mouse lung rudiment stained with antibodies to CD31 to visualize the growing capillary endothelium. Notice that the expansion of each epithelial bud is accompanied by extension and growth of a surrounding capillary plexus that envelopes each expanding lobule. Mechanical coupling between the epithelium and endothelium may help to orchestrate growth of the entire organ.

2004). Thus, there must be some higher level of information processing that can explain this link between cell structure and function which is so critical for the establishment of the local growth differentials that underlie developmental control.

\section{Cellular decision-making at the genome-wide level}

Biologists commonly assume that cell fate switching is controlled through activation of a specific series of regulatory events that "instruct" the cell to express one distinct phenotype or another and thus, they speak of a "growth pathway" or a "differentiation pathway". But when a cell turns on its growth program, it also must turn off its differentiation, apoptosis and motility programs in order to function effectively. The importance of this robust switching behavior is made even more evident by recent genomic and proteomic studies which show that molecular pathways in the cell form a single large connected network ("giant component") that spans almost the entire genome (Callaway etal., 2001, Jeong etal., 2001, Marcotte, 2001). If virtually all of the genes and proteins of the genome-wide regulatory network are effectively regulated as a single integrated system, then how are cells able to reliably integrate multiple conflicting signals and respond by selecting one of just a few possible cell fates?

The observation that varying cell shape continuously from round to spread produces abrupt changes in cell fate (apoptosis or differentiation or growth) is reminiscent of a "phase transition" in physical systems. Simple inorganic materials, such as water, exhibit similar behavior (e.g., transition between ice, water and steam as the temperature is raised). The macroscopic (systemlevel) features of these inorganic materials are known to be emergent properties of the network of interactions among their numerous components. For example, the melting behavior of ice is governed by the lattice characteristics of water molecules (a single water molecule has no melting point). We therefore began to explore whether different stable cell fates arise in an analogous 
manner given that they similarly emerge out of a network of gene and protein regulatory interactions.

This work, led by Sui Huang in my group, was based on past work from the Complexity field by Stuart Kauffman (Kauffman, $1969,1993)$ which has revealed that stable states, known as "attractors", will spontaneously emerge in large interconnected networks that exhibit a particular class of network architecture because of dynamic constraints imposed by the regulatory interactions. Importantly, recent advances in proteomics and genomics have revealed that biological networks exhibit precisely this type of network architecture (Glass and Hill, 1998, Jeong et al., 2001, Fox and Hill, 2001). We therefore have proposed that the robust cell fates that mammalian cells express (e.g., growth, differentiation, motility, apoptosis) may similarly represent attractor states in the genome-wide regulatory network (Huang and Ingber, 2000).

Conceptually, the existence of stable attractors within the overall potential gene landscape is analogous to the view of developmental control first presented by the embryologist Waddington in the middle of the last century (Waddington, 1956). He noticed that different developmental lineages are mutually exclusive and robust in that a single cell will rarely, if ever, exhibit two different phenotypes at once. To visualize this phenomenon, he used the analogy of a ball rolling over a landscape with hills and valleys: the ball (representing the phenotypic state of any cell) will progressively roll down any hill it encounters and come to rest in one or other of the various valleys below, but it will never stop in two valleys simultaneously (Fig. 8). In Kauffman's dynamic network models, these valleys represent "basins of attraction" and where the ball comes to rest at the low point in the valley is the "attractor". Thus, at any point in time, the position of the ball would represent the internal state of the cell which, when activated by some stimulus, would roll through the gene state space (hillsides) always falling into one of the same group of potential cell fates (valleys) (Fig. 8).

We first explored the possibility that this is how cells carry out information processing by developing computational models of cell shape-dependent growth control based on Boolean networks (networks that utilize on/off "logic gates" to model regulatory interactions) (Huang and Ingber, 2000) similar to those used by Kauffmann in past mathematical modeling studies (Kauffman, 1969,1993). However, our models incorporated experimental data relating to the activities of known growth signaling molecules (e.g., p27, cyclin $D 1, R b)$ that we measured in experiments with living cells in which cell shape, ECM adhesion and growth factors were controlled independently (Huang et al., 1998). Out of this model emerged a cycling attractor state that corresponded to the mammalian cell cycle, as well as two other attractors that mimicked the distinct resting "G0" states induced by serum-starvation versus ECM detachment (Huang and Ingber, 2000). These data demonstrated that the network of interactions, rather than any individual signaling component or module, is the essential ingredient for production of ordered, system-level behavior, at least in this simplified model.

Importantly, we recently were able to demonstrate that cell fates represent attractor states in the genome-wide regulatory network by analyzing dynamic changes of genome-wide gene profiles during induction of a cell fate switch in human HL60 promyelocytic precursor cells (Huang et al., 2005). These cells were induced to differentiate into neutrophils by treatment with two distinct stimuli, one highly specific (all trans-retinoic acid) and one non-specific (dimethylsulfoxide). These studies using gene microarrays to probe the genome-wide gene profile at multiple time points confirmed that the differentiation of human promyelocytes into neutrophils triggered by either stimulus occurred along two distinct gene expression state space trajectories that first diverged, but then converged across thousands of dimensions (different genes) as the cells transitioned into the common differentiated phenotype. These studies therefore demonstrated that cells in both treatment groups visited different sites as they crossed the peak and passed from one valley to another, but they then converged to come to rest in the same common attractor (i.e., neutrophil state) at the low point in the second valley. These findings also provide a mechanistic basis for Waddington's "epigenetic landscape" that was initially proposed as an intuitive metaphor to capture the typical features of cell fate dynamics during embryological development. In short, our work suggests that the relative position of a cell in this landscape determines its developmental potential, rather than cell fate resulting from activation of a particular "instructive" pathway or linear series of specific genes.

The existence of attractors in the genome-wide regulatory network is important because it can explain how a non-specific stimulus like cell shape distortion might have been harnessed by evolution to impact the same biochemical machinery responsible for distinct cell fate switches that are actuated by soluble factors that bind to specific cell surface receptors (Ingber, 2003b). Even more important, it explains how cells can simultaneously sense multiple inputs - chemical, adhesive and mechanical - and yet only switch on one of a limited number of specific and reproducible phenotypic responses (e.g., growth or differentiation or apoptosis). But what is most intriguing is that multiple regulatory elements (e.g., genes, signaling proteins) within the whole network must change simultaneously in order to produce an attractor switch. This may explain how cell shape changes are able to control cell fate switching given that distortion of the cell and cytoskeleton likely impacts many cytoskeletal-associated signaling molecules at once (Ingber, 2003b). In this manner, cells and tissues are precisely constructed so as to optimally integrate their structural and information processing networks in order to produce spatial variations in cell growth, function and discrete developmental lineage switches, that optimally fit their local mechanical and chemical environment.

\section{Implications for developmental biology}

The formation of tissues and organs with specialized form and function during embryogenesis requires precise temporal and spatial coordination of cell growth and function (Ingber and Jamieson, 1985, Huang and Ingber, 1999). Our work suggests that to generate structures that exhibit localized bending, budding, or branching, one cell or a small group of cells must divide or migrate locally, whereas the neighboring cells must remain quiescent. Each cell must therefore be able to correctly interpret multiple mechanical and chemical cues from its microenvironment and make the appropriate developmental decision. Clearly, regional production of soluble cues (e.g., growth factors) and chemical gradients can drive tissue expansion and pattern formation in developing organs (Metzger and Krasnow, 1999), as they do during establishment of polarity in early embryogenesis. However, the sharp differentials in cell growth and migration that are respon- 


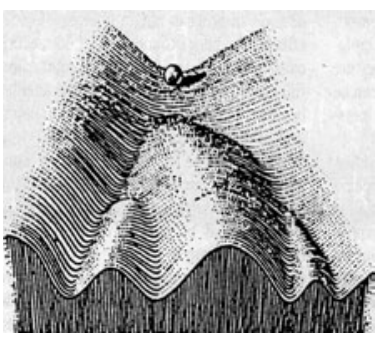

Waddington's Epigenetic Landscape

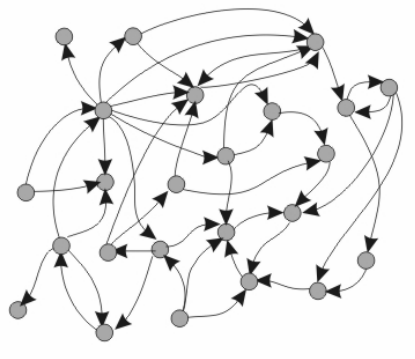

Genome-Wide Regulatory Network

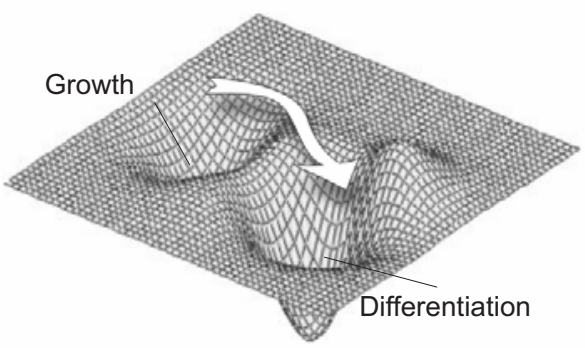

Cell Fate Switching in an Attractor Landscape

Fig. 8. The epigenetic landscape: from metaphor to mechanism. (Left) The model Waddington first proposed as a metaphor in 1940 to explain how a cell decides between "discrete» fates during development. Recent work suggests that this concept may be regarded as a manifestation of dynamic constraints of the underlying genome-wide regulatory network (center) which creates a gene state space with the character of an "attractor landscape" (right). In this landscape, distinct cell fates, such as growth, differentiation, apoptosis and different stem cell lineages represent distinct valleys (attractors) in the common landscape. Cells may take multiple paths to cross over a hill, however, they will roll until they come to a stop at a common end point at the bottom of the next valley; these low points or attractors are the limited number of default states that a cell can exhibit. (Image at left reprinted from Waddington, 1956; for more details, see Huang and Ingber, 2000, Ingber, 2003b, Huang et al., 2005).

sible for patterning in many growing tissues occur on the micrometer scale, such that neighboring cells can exhibit entirely opposite responses. Our results suggest that these spatial differentials in growth and migration may be controlled by local variations in the physical or mechanical properties of the tissue microenvironment, such as changes in mechanical interactions between cells and their ECM due to regional variations in ECM compliance or cell contractility.

This work also has important implications for earlier stages of embryological development. For example, formation of the dorsoventral axis in the early gastrula-stage Drosophila melanogaster embryo appears to be controlled mechanically by normal morphogenetic movements during mesoderm invagination that produce local cell compression. Resulting cell distortion induces local signal transduction events (e.g., nuclear translocation of Armadillo, Twist gene transcription) and similar effects can by produced by external application of mechanical force to these cells with a micropipette (Farge, 2003). Interestingly, basement membrane thinning, analogous to that observed in regions of cell outgrowth during later tissue development, is also observed in the primitive streak where the mesoderm forms through sprouting of the ectoderm into the blastocoel space (Sanders, 1982). Mesodermal cells exert greater tensional forces than epithelial cells (Foty et al., 1996) and thus these cells may pull downward on the overlying ectoderm as they move inward. Traction forces in mesodermal cells may pull downward on the overlying ectoderm, cause indentation of the tissue and thereby, physically transform the primitive streak into the primitive "groove". This local increase in tensional forces also may promote increased cell proliferation and directional migration, as is observed in this region during primitive streak invagination.

Subsequent formation of specialized tissue structures during gastrulation results from extension and contraction of the cells that comprise these tissues (Beloussov et al., 1997, Keller et al., 2003), as described above. These forces are resisted by the material properties (stiffness/compliance) of nearby ECM scaffolds until they again come into balance and new stable 3D tissue forms are created. Contraction waves that span the entire amphibian embryo also have been observed during gastrulation; these mechanically generated wave forms might provide a higher level mechanism to orchestrate the time and location of new tissue remodeling events over larger regions of the embryo, such as during primary neura induction (Brodland et al., 1994).

As described above, tension-dependent compaction of cells is critical during the morula stage of development. Localized condensation of mesenchyme is also often a hallmark of where new epithelial tissue outgrowth will initiate during later stages of embryogenesis (e.g., during limb bud outgrowth). This process undoubtedly results from either a local increase in mesenchymal cell contraction (i.e., rise in cytoskeletal tension), a regional decrease in ECM rigidity (e.g., due to local degradation), or both. Interestingly, the mesenchyme of different tissues that produce different organotypic branching patterns (e.g., acinar versus lobular) exhibit different levels of contractility (Nogawa and Nakanishi, 1987). Finally, as observed during lung development, tensional forces transmitted between different tissues (e.g., epithelium and endothelium) also may help to influence whole organ formation at a higher level. Elongation of bone rudiments may similarly promote extension and growth of surrounding muscle, nerves and vessels during limb development, whereas the contraction of the elongated muscles may feed back to promote bone growth and differentiation. In this manner, tissue and organ patterns may represent "maps of underlying force distributions" as first proposed by D'Arcy Thompson almost a century ago (Thompson, 1952). However, the work reviewed here suggests even more: these "invisible" force maps may be actively responsible for controlling cell growth and tissue development, as previously proposed (Ingber and Jamieson, 1985, Huang and Ingber, 1999).

\section{Conclusion}

Taken together, our work suggests that mechanical forces generated in the cytoskeleton of living cells and exerted on their adhesions to ECM and neighboring cells play a central role in control of tissue development during both early and late stages of 
embryogenesis. Changes in the cellular force balance that alter integrin signaling pathways and produce global changes in cytoskeletal structure are central to this process. The local mechanical environment may be altered by changing the level of cell contractility, the mechanical compliance of the ECM through biochemical remodeling, or the number or size of cells packed within a tissue volume that is physically restricted by a relatively rigid (non-extensible) ECM.

Cells sense these local changes in mechanical cues and integrate them with other chemical and adhesive signals in their local microenvironment. For cells to switch locally between different stable phenotypes (e.g., growth vs. differentiation; different stem cell lineages), multiple genes or other regulatory elements must simultaneously alter their activity status. The cytoskeleton, with its multiple associated signaling components, is perfectly positioned to provide this multiplexed switching activity while simultaneously providing a mechanism for mechanical forces to influence this response. Thus, although the field of developmental biology has been dominated by a search for gene switches and soluble regulators over the past century, the time might be ripe to reexplore the mechanical basis of tissue development, with a specific focus on how mechanics and chemistry are integrated at the molecular, cellular and tissue levels.

\section{Acknowledgements}

This work was supported by grants from NIH and NASA (to D.E.I.) and an NSF grant in support of the MRSEC at Harvard University. I would like to especially thank Kimberly Moore, Eben Alsberg, Tom Polte, SuiHuang, Chris Chen, Amy Brock and Cliff Brangwynne for their assistance with the preparation of the figures.

\section{References}

ADAMS, D. S., KELLER, R. and KOEHL, M. A. (1990). The mechanics of notochord elongation, straightening and stiffening in the embryo of Xenopus laevis. Development 110: 115-130.

ALENGHAT, F. J. and INGBER, D. E. (2002). Mechanotransduction: all signals point to cytoskeleton, matrix and integrins. SCi STKE2002: PE6.

AUSPRUNK, D. H. and FOLKMAN, J. (1977). Migration and proliferation of endothelial cells in preformed and newly formed blood vessels during tumor angiogenesis. Microvasc Res 14: 53-65.

BELOUSSOV, L. V., DORFMAN, J. G. and CHERDANTZEV, V. G. (1975). Mechanical stresses and morphological patterns in amphibian embryos. $J$ Embryol Exp Morpho/34: 559-574.

BELOUSSOV, L. V., KAZAKOVA, N. I., LUCHINSKAIA, N. N. and NOVOSELOV, V. V. (1997). Studies in developmental cytomechanic. Int J Dev Bio/41: 793799.

BELOUSSOV, L. V., LAKIREV, A. V., NAUMIDI, II and NOVOSELOV, V. V. (1990). Effects of relaxation of mechanical tensions upon the early morphogenesis of Xenopus laevis embryos. Int J Dev Bio/34: 409-419.

BELOUSSOV, L. V., LOUCHINSKAIA, N. N. and STEIN, A. A. (2000). Tensiondependent collective cell movements in the early gastrula ectoderm of Xenopus laevis embryos. Dev Genes Evo/210: 92-104.

BEN-ZE'EV, A., FARMER, S. R. and PENMAN, S. (1980) Protein synthesis requires cell-surface contact while nuclear events respond to cell shape in anchorage-dependent fibroblasts. Ce//21, 365-372.

BEN-ZE'EV, A., ROBINSON, G. S., BUCHER, N. L. and FARMER, S. R. (1988). Cell-cell and cell-matrix interactions differentially regulate the expression of hepatic and cytoskeletal genes in primary cultures of rat hepatocytes. Proc Nat/ Acad Sci USA 85: 2161-2165.

BENINGO, K. A., DEMBO, M., KAVERINA, I., SMALL, J. V. and WANG, Y. L. (2001). Nascent focal adhesions are responsible for the generation of strong propulsive forces in migrating fibroblasts. J Cel/ Bio/153: 881-888.
BERNFIELD, M. R. and BANERJEE, S. D. (1978). The basal lamina in epithelialmesenchymal interactions. In "Biology and Chemistry of Basement Membranes.» (N. Kefalides, Ed.), pp. 137-148. Academic Press, New York.

BRAY, D. (1979). Mechanical tension produced by nerve cells in tissue culture. $J$ Cell Sci37: 391-410.

BROCK, A., CHANG, E., HO, C. C., LEDUC, P., JIANG, X., WHITESIDES, G. M. and INGBER, D. E. (2003). Geometric determinants of directional cell motility revealed using microcontact printing. Langmuir 19: 1611-1617.

BRODLAND, G. W., GORDON, R., SCOTT, M. J., BJORKLUND, N. K., LUCHKA, K. B., MARTIN, C. C., MATUGA, C., GLOBUS, M., VETHAMANY-GLOBUS, S. and SHU, D. (1994). Furrowing surface contraction wave coincident with primary neural induction in amphibian embryos. J Morpho/219: 131-142.

CALLAWAY, D. S., HOPCROFT, J. E., KLEINBERG, J. M., NEWMAN, M. E. and STROGATZ, S. H. (2001). Are randomly grown graphs really random? Phys Rev E Stat Nonlin Soft Matter Phys 64: 041902.

CHEN, C. S., MRKSICH, M., HUANG, S., WHITESIDES, G. M. and INGBER, D. E. (1997). Geometric control of cell life and death. Science 276: 1425-1428.

CHEN, C. S., TAN, J. and TIEN, J. (2004). Mechanotransduction at cell-matrix and cell-cell contacts. Annual Review of Biomedical Engineering 6: 275-302.

CLAYTON, L., HALL, A. and JOHNSON, M. H. (1999). A role for Rho-like GTPases in the polarisation of mouse eight-cell blastomeres. Dev Bio/205: 322-331.

CONDRON, B. G. and ZINN, K. (1997). Regulated neurite tension as a mechanism for determination of neuronal arbor geometries in vivo. Curr Bio/7: 813-816.

DAVID, G. and BERNFIELD, M. R. (1979). Collagen reduces glycosaminoglycan degradation by cultured mammary epithelial cells: possible mechanism for basal lamina formation. Proc Nat/ Acad Sci USA 76: 786-790.

DE VRIES, W. N., EVSIKOV, A. V., HAAC, B. E., FANCHER, K. S., HOLBROOK, A. E., KEMLER, R., SOLTER, D. and KNOWLES, B. B. (2004). Maternal betacatenin and E-cadherin in mouse development. Development 131: 4435-4445.

DIKE, L. E., CHEN, C. S., MRKSICH, M., TIEN, J., WHITESIDES, G. M. and INGBER, D. E. (1999). Geometric control of switching between growth, apoptosis and differentiation during angiogenesis using micropatterned substrates. In Vitro Cell Dev Biol Anim 35: 441-448.

EKBlom, P., AlitAlo, K., VAHERI, A., TIMPL, R. and SAXEN, L. (1980). Induction of a basement membrane glycoprotein in embryonic kidney: possible role of laminin in morphogenesis. Proc Nat/ Acad Sci USA 77: 485-489.

ENGLER, A. J., GRIFFIN, M. A., SEN, S., BONNEMANN, C. G., SWEENEY, H. L. and DISCHER, D. E. (2004). Myotubes differentiate optimally on substrates with tissue-like stiffness: pathological implications for soft or stiff microenvironments. J Cel/ Biol166: 877-887.

FARGE, E. (2003). Mechanical induction of Twist in the Drosophila foregut/ stomodeal primordium. Curr Bio/13: 1365-1377.

FOLKMAN, J. and MOSCONA, A. (1978). Role of cell shape in growth control. Nature 273: 345-349.

FOTY, R. A., PFleGER, C. M., FORGACS, G. and STEINBERG, M. S. (1996). Surface tensions of embryonic tissues predict their mutual envelopment behavior. Development 122: 1611-1620.

FOX, J. J. and HILL, C. C. (2001). From topology to dynamics in biochemical networks. Chaos 11: 809-815.

FULLER, B. (1961). Tensegrity. Portfolio Artnews Annual4: 112-127.

GEIGER, B., YEHUDA-LEVENBERG, S. and BERSHADSKY, A. D. (1995) Molecular interactions in the submembrane plaque of cell-cell and cell-matrix adhesions. Acta Anat 154: 46-62.

GEIGER, B., BERSHADSKY, A., PANKOV, R. and YAMADA, K. M. (2001). Transmembrane crosstalk between the extracellular matrix-cytoskeleton crosstalk. Nat Rev Mol Cel/ Bio/2: 793-805.

GLASS, L. and HILL, C. C. (1998). Ordered and disordered dynamics in random networks. Europhys. Lett. 41(6): pp. 599-604.

GLOWACKI, J., TREPMAN, E. and FOLKMAN, J. (1983). Cell shape and phenotypic expression in chondrocytes. Proc Soc Exp Biol Med 172: 93-98.

GORDON, R. and BRODLAND, G. W. (1987). The cytoskeletal mechanics of brain morphogenesis. Cell state splitters cause primary neural induction. Cell Biophys 11: 177-238.

HARDIN, J. and KELLER, R. (1988). The behaviour and function of bottle cells during gastrulation of Xenopus laevis. Development 103: 211-230. 
HARRIS, A. K., WILD, P. and STOPAK, D. (1980). Silicone rubber substrata: a new wrinkle in the study of cell locomotion. Science 208: 177-179.

HU, S., CHEN, J., FABRY, B., NUMAGUCHI, Y., GOULDSTONE, A., INGBER, D. E., FREDBERG, J. J., BUTLER, J. P. and WANG, N. (2003). Intracellular stress tomography reveals stress focusing and structural anisotropy in cytoskeleton of living cells. Am J Physiol Cell Physio/285: C1082-C1090.

HU, S., CHEN, J. and WANG, N. (2004a). Cell spreading controls balance of prestress by microtubules and extracellular matrix. Front Biosci9: 2177-2182.

HU, S. H., EBERHARD, L., CHEN, J. X., LOVE, J. C., BUTLER, J. P., FREDBERG, J. J., WHITESIDES, G. M. and WANG, N. (2004b). Mechanical anisotropy of adherent cells probed by a three-dimensional magnetic twisting device. American Journal of Physiology-Cell Physiology 287: C1184-C1191.

HUANG, S., CHEN, C. S. and INGBER, D. E. (1998). Control of cyclin D1, p27(Kip1) and cell cycle progression in human capillary endothelial cells by cell shape and cytoskeletal tension. Mol Biol Cel/9: 3179-3193.

HUANG, S., EICHLER, G., BAR-YAAM, Y. and INGBER, D. (2005). Cell fate as high-dimensional attractor of a complex gene regulatory network. Phys. Rev. Let. 94, 128701.

HUANG, S. and INGBER, D. E. (1999). The structural and mechanical complexity of cell-growth control. Nat Cel/ Biol1: E131-138.

HUANG, S. and INGBER, D. E. (2000). Shape-dependent control of cell growth, differentiation and apoptosis: switching between attractors in cell regulatory networks. Exp Cell Res 261: 91-103.

INGBER, D. E. (1990). Fibronectin controls capillary endothelial cell growth by modulating cell shape. Proc Natl Acad Sci USA 87: 3579-3583.

INGBER, D. E. (1993a). Cellular tensegrity: defining new rules of biological design that govern the cytoskeleton. J Cel/ Sci104: 613-627.

INGBER, D. E. (1993b). The riddle of morphogenesis: a question of solution chemistry or molecular cell engineering? Cel/75: 1249-1252.

INGBER, D. E. (2002). Mechanical Signaling and the Cellular Response to Extracellular Matrix in Angiogenesis and Cardiovascular Physiology. Circ. Res. 91: 877-887.

INGBER, D. E. (2003a). Tensegrity I. Cell structure and hierarchical systems biology. J Cell Sci116: 1157-1173.

INGBER, D. E. (2003b). Tensegrity II. How structural networks influence cellular information processing networks. J Cel/ Sci116: 1397-1408.

INGBER, D. E. and FOLKMAN, J. (1989). Mechanochemical switching between growth and differentiation during fibroblast growth factor-stimulated angiogenesis in vitro: role of extracellular matrix. J Cel/ Bio/109: 317-330.

INGBER, D. and JAMIESON, J. D. (1985). «Cells as tensegrity structures: architectural regulation of histodifferentiation by physical forces tranduced over basement membrane.» Academic Press, Orlando, pp. 13-32.

INGBER, D. E., MADRI, J. A. and FOLKMAN, J. (1986). A possible mechanism for inhibition of angiogenesis by angiostatic steroids: induction of capillary basement membrane dissolution. Endocrino/119: 1768-1775.

INGBER, D. E., MADRI, J. A. and JAMIESON, J. D. (1981). Role of basal lamina in the neoplastic disorganization of tissue architecture. Proc Nat/ Acad Sci USA 78: 3901-3905

INGBER, D. E., MADRI, J. A. and JAMIESON, J. D. (1986). Basement membrane as a spatial organizer of polarized epithelia. Exogenous basement membrane reorients pancreatic epithelial tumor cells in vitro. Am J Patho/122: 129-139.

INGBER, D. E., PRUSTY, D., FRANGIONI, J. V., CRAGOE, E. J., JR., LECHENE, C. and SCHWARTZ, M. A. (1990). Control of intracellular $\mathrm{pH}$ and growth by fibronectin in capillary endothelial cells. J Cel/ Bio/110: 1803-1811.

JEONG, H., MASON, S. P., BARABASI, A. L. and OLTVAI, Z. N. (2001). Lethality and centrality in protein networks. Nature 411: 41-42.

JOSHI, H. C., CHU, D., BUXBAUM, R. E. and HEIDEMANN, S. R. (1985). Tension and compression in the cytoskeleton of PC 12 neurites. JCel/ Bio/101: 697-705.

KAUFFMAN, S. A. (1969). Metabolic stability and epigenesis in randomly constructed genetic nets. J Theor Bio/22: 437-467.

KAUFFMAN, S. A. (1993). "The Origins of Order.» Oxford Univ. Press, New York.

KAWANO, Y., FUKATA, Y., OSHIRO, N., AMANO, M., NAKAMURA, T., ITO, M., MATSUMURA, F., INAGAKI, M. and KAIBUCHI, K. (1999). Phosphorylation of myosin-binding subunit (MBS) of myosin phosphatase by Rho-kinase in vivo. $J$ Cell Biol 147: 1023-1038.
KELLER, R., DAVIDSON, L. A. and SHOOK, D. R. (2003). How we are shaped: the biomechanics of gastrulation. Differentiation 71: 171-205.

KELLER, R. E. (1980). The cellular basis of epiboly: an SEM study of deep-cell rearrangement during gastrulation in Xenopus laevis. J Embryol Exp Morphol 60: 201-234.

KIMURA, K., ITO, M., AMANO, M., CHIHARA, K., FUKATA, Y., NAKAFUKU, M., YAMAMORI, B., FENG, J., NAKANO, T., OKAWA, K., IWAMATSU, A. and KAIBUCHI, K. (1996). Regulation of myosin phosphatase by Rho and Rhoassociated kinase (Rho-kinase). Science 273: 245-248.

KO, K. S., ARORA, P. D. and MCCULLOCH, C. A. (2001) Cadherins mediate intercellular mechanical signaling in fibroblasts by activation of stretch-sensitive calcium-permeable channels. J Biol Chem 276: 35967-35977.

KORFF, T. and AUGUSTIN, H. G. (1999). Tensional forces in fibrillar extracellular matrices control directional capillary sprouting. J Cell Sci112 (Pt 19): 32493258.

LAMOUREUX, P., RUTHEL, G., BUXBAUM, R. E. and HEIDEMANN, S. R. (2002). Mechanical tension can specify axonal fate in hippocampal neurons. J Cell Biol 159: 499-508.

LEIVO, I. (1983). Structure and composition of early basement membranes: studies with early embryos and teratocarcinoma cells. Med Bio/61: 1-30.

LENOIR, T. (1982). «The Strategy of Life: Teleology and Mechanics in Nineteenth Century German Biology.» University of Chicago Press, Chicago.

LI, F. and HIGGS, H. N. (2003). The mouse Formin mDia1 is a potent actin nucleation factor regulated by autoinhibition. Curr Bio/13: 1335-1340.

LI, M. L., AGGELER, J., FARSON, D. A., HATIER, C., HASSELL, J. and BISSELL, M. J. (1987). Influence of a reconstituted basement membrane and its components on casein gene expression and secretion in mouse mammary epithelial cells. Proc Nat/ Acad Sci USA 84: 136-140.

MAMMOTO, A., HUANG, S., MOORE, K., OH, P. and INGBER, D. E. (2004). Role of RhoA, mDia and ROCK in cell shape-dependent control of the Skp2-p27kip1 pathway and the G1/S transition. J Bio/ Chem 279: 26323-26330.

MANIOTIS, A. J., CHEN, C. S. and INGBER, D. E. (1997). Demonstration of mechanical connections between integrins, cytoskeletal filaments and nucleoplasm that stabilize nuclear structure. Proc Natl Acad Sci USA 94: 849-854.

MARCOTTE, E. M. (2001). The path not taken. Nat Biotechno/19: 626-627.

MCBEATH, R., PIRONE, D. M., NELSON, C. M., BHADRIRAJU, K. and CHEN, C S. (2004). Cell shape, cytoskeletal tension and $\mathrm{RhoA}$ regulate stem cell lineage commitment. Dev Ce//6: 483-495.

METZGER, R. J. and KRASNOW, M. A. (1999). Genetic control of branching morphogenesis. Science 284: 1635-1639.

MEYER, C. J., ALENGHAT, F. J., RIM, P., FONG, J. H., FABRY, B. and INGBER, D. E. (2000). Mechanical control of cyclic AMP signalling and gene transcription through integrins. Nat Cell Bio/2: 666-668.

MIYAMOTO, S., AKIYAMA, S. K. and YAMADA, K. M. (1995). Synergistic roles for receptor occupancy and aggregation in integrin transmembrane function. Science 267: 883-885.

MOONEY, D., HANSEN, L., VACANTI, J., LANGER, R., FARMER, S. and INGBER, D. (1992). Switching from differentiation to growth in hepatocytes: control by extracellular matrix. J Cel/ Physio/ 151: 497-505.

MOORE, K. A., POLTE, T., HUANG, S., SHI, B., ALSBERG, E., SUNDAY, M. E. and INGBER, D. E. (2005). Control of basement membrane remodeling and epithelial branching morphogenesis in embryonic lung by Rho and cytoskeletal tension. Developmental Dynamics 232: 268-281.

MOORE, S. W., KELLER, R. E. and KOEHL, M. A. (1995). The dorsal involuting marginal zone stiffens anisotropically during its convergent extension in the gastrula of Xenopus laevis. Development 121: 3131-3140.

NILAND, S., CREMER, A., FLUCK, J., EBLE, J. A., KRIEG, T. and SOLLBERG, S. (2001). Contraction-dependent apoptosis of normal dermal fibroblasts. J/nvest Dermato/116: 686-692.

NOGAWA, H., MORITA, K. and CARDOSO, W. V. (1998). Bud formation precedes the appearance of differential cell proliferation during branching morphogenesis of mouse lung epithelium in vitro. Dev Dyn 213: 228-235.

NOGAWA, H. and NAKANISHI, Y. (1987). Mechanical aspects of the mesenchymal influence on epithelial branching morphogenesis of mouse salivary gland. Development 101: 491-500. 
OPAS, M. (1989). Expression of the differentiated phenotype by epithelial cells in vitro is regulated by both biochemistry and mechanics of the substratum. Dev Bio/131: 281-293.

PARKER, K. K., BROCK, A. L., BRANGWYNNE, C., MANNIX, R. J., WANG, N., OSTUNI, E., GEISSE, N. A., ADAMS, J. C., WHITESIDES, G. M. and INGBER, D. E. (2002). Directional control of lamellipodia extension by constraining cell shape and orienting cell tractional forces. Faseb J16: 1195-1204.

PLOPPER, G. E., MCNAMEE, H. P., DIKE, L. E., BOJANOWSKI, K. and INGBER, D. E. (1995). Convergence of integrin and growth factor receptor signaling pathways within the focal adhesion complex. Mol Biol Ce//6: 1349-1365.

POLTE, T. R., EICHLER, G. S., WANG, N. and INGBER, D. E. (2004). Extracellular matrix controls myosin light chain phosphorylation and cell contractility through modulation of cell shape and cytoskeletal prestress. Am J Physiol Cell Physiol 286: C518-C528.

POTARD, U. S., BUTLER, J. P. and WANG, M. (1997). Cytoskeletal mechanics in confluent epithelial cells probed through integrins and E-cadherins. $A m J$ Physio/272: C1654-1663.

RIETHMACHER, D., BRINKMANN, V. and BIRCHMEIER, C. (1995). A targeted mutation in the mouse $\mathrm{E}$-cadherin gene results in defective preimplantation development. Proc Nat/ Acad Sci USA 92: 855-859.

RODRIGUEZ-BOULAN, E., PASKIET, K. T. and SABATINI, D. D. (1983). Assembly of enveloped viruses in Madin-Darby canine kidney cells: polarized budding from single attached cells and from clusters of cells in suspension. $J$ Cell Biol 96: 866-874.

ROSENBLATT, N., HU, S., CHEN, J., WANG, N. and STAMENOVIC, D. (2004). Distending stress of the cytoskeleton is a key determinant of cell rheological behavior.nBiochem Biophys Res Commun 321: 617-622.

RUOSLAHTI, E. (1991). Integrins. J Clin Invest 87: 1-5.

SANDERS, E. J. (1982). Ultrastructural immunocytochemical localization of fibronectin in the early chick embryo. J Embryol Exp Morpho/71: 155-170.

SCHMIDT, C. E., HORWITZ, A. F., LAUFFENBURGER, D. A. and SHEETZ, M. P. (1993). Integrin-cytoskeletal interactions in migrating fibroblasts are dynamic, asymmetric and regulated. $J$ Cel/ Bio/123: 977-991.

SIMIAN, M., HIRAI, Y., NAVRE, M., WERB, Z., LOCHTER, A. and BISSELL, M. J.
(2001). The interplay of matrix metalloproteinases, morphogens and growth factors is necessary for branching of mammary epithelial cells. Development 128: 3117-3131.

SINGHVI, R., KUMAR, A., LOPEZ, G. P., STEPHANOPOULOS, G. N., WANG, D. I., WHITESIDES, G. M. and INGBER, D. E. (1994). Engineering cell shape and function. Science 264: 696-698.

TAN, J. L., TIEN, J., PIRONE, D. M., GRAY, D. S., BHADRIRAJU, K. and CHEN, C. S. (2003). Cells lying on a bed of microneedles: an approach to isolate mechanical force. Proc Nat/ Acad Sci USA 100: 1484-1489.

THOMPSON, D. W. (1952). «On Growth and Form.» Cambridge University Press, London.

TRELSTAD, R. L., HAYASHI, A., HAYASHI, K. and DONAHOE, P. K. (1982). The epithelial-mesenchymal interface of the male rate Mullerian duct: loss of basement membrane integrity and ductal regression. Dev Bio/92: 27-40.

WADDINGTON, C. H. (1956). «Principles of Embryology.» Allen \& Unwin Ltd, London.

WANG, N., BUTLER, J. P. and INGBER, D. E. (1993). Mechanotransduction across the cell surface and through the cytoskeleton. Science 260: 1124-1127.

WANG, N., NARUSE, K., STAMENOVIC, D., FREDBERG, J. J., MIJAILOVICH, S. M., TOLIC-NORRELYKKE, I. M., POLTE, T., MANNIX, R. and INGBER, D. E. (2001). Mechanical behavior in living cells consistent with the tensegrity model. Proc Natl Acad Sci USA 98: 7765-7770.

WANG, N., OSTUNI, E., WHITESIDES, G. M. and INGBER, D. E. (2002). Micropatterning tractional forces in living cells. Cell Motil Cytoskeleton 52: 97106.

WICHA, M. S., LIOTTA, L. A., VONDERHAAR, B. K. and KIDWELL, W. R. (1980). Effects of inhibition of basement membrane collagen deposition on rat mammary gland development. Dev Bio/80: 253-256.

YAN, L., MOSES, M. A., HUANG, S. and INGBER, D. E. (2000). Adhesiondependent control of matrix metalloproteinase-2 activation in human capillary endothelial cells. J Cel/ Sci113: 3979-3987.

YURCHENCO, P. D. and RUBEN, G. C. (1988). Type IV collagen lateral associations in the EHS tumor matrix. Comparison with amniotic and in vitro networks. Am J Patho/ 132: 278-291. 